\title{
Voice, Silence, and Quiet Resistance in Percival Everett's Glyph
}

\author{
Nathalie Aghoro
}

\begin{abstract}
This article investigates how the refusal to speak becomes a resonant expression of protest in Percival Everett's novel Glyph (1999). It offers a reading of Everett's experimental work as generating a literary soundscape of the quiet voice to reflect on the functions of sonic absence in the politics and aesthetics of resistance. With Kevin Quashie's work The Sovereignty of Quiet (2012) and Fred Moten's writings on the significance of sound in black radical aesthetics as conceptual bridges, it seeks to establish that Glyph explores the boundaries and possibilities of black self-determination in the American socio-political context as it pitches the acoustics of silence and voice against the mute textuality of the book. Along these lines, the explicit refusal of a voice to speak in Glyph simultaneously reveals and complicates the dynamics of racialization in literary imaginations and reading practices.
\end{abstract}

Suggested Citation: Aghoro, Nathalie. "Voice, Silence, and Quiet Resistance in Percival Everett's Glyph." JAAAS: Journal of the Austrian Association for American Studies 1, no. 2 (2020): 201-215, DOI: 10.4706o/jaaas.v1i2.35.

Keywords: $\quad$ African American literature; erasure; literary soundscape; sonic absence; ethics of listening

Peer Review: $\quad$ This article was reviewed by the issue's guest editors and an external peer reviewer.

Copyright: $\quad$ C 2020 Nathalie Aghoro. This is an open-access article distributed under the terms of the Creative Commons Attribution 4.0 International License (CCBY 4.0), which allows for the unrestricted use, distribution, and reproduction in any medium, provided the original author and source are credited. 


\section{Voice, Silence, and Quiet Resistance in Percival Everett's Glyph}

\section{Nathalie Aghoro}

$\mathrm{H}$ ow much dissent can a quiet voice express and what objections could its silence impart? This question informs the present inquiry about the apparent paradox of quiet resistance in Percival Everett's Glyph-a novel that presents itself in the guise of a deconstruction paper featuring a black protagonist who proudly proclaims his sonic erasure from an obtrusive and noisy world: "I was a baby fat with words, but I made no sound." The stark contrast between the manifest surplus of speech and the obliteration of sound brings to mind both Kevin Quashie's ideas on the agency of the quiet and Fred Moten's take on the intricate connections between sound, vision, and power. For Quashie, "Quiet is the subjectivity that permits the vagary of humanity and that pushes against social identity and its narrow corners," while Moten is "interested in the convergence of blackness and the irreducible sound of necessarily visual performance at the scene of objection."2 When read together, these two quotations build conceptual bridges between notions of blackness, resistance, quiet, and voice in Everett's literary experiment.

Sounds such as the scream, the voice, or musical improvisation suffuse black radical aesthetics, according to Moten, because they resist the predominance of the visual that black performance is subjected to in American culture. In In the Break (2003), Moten seeks out the auditory elements in photography, literature, jazz, and blues that break "the ocularcentric structuration of recognition." Along these lines, the conjunction of the silence of Everett's character in Glyph-who reveals his blackness only when it becomes unavoidable in the story-with the excess of words that build up in his small body, making it "fat," connotes a tension, a resistance to the acoustic expression of his thoughts. The sound of his voice remains internalized, devoid of an audible trace. However, the mentioning of this soundlessness alone opens a discursive space for the question of whether he struggles against raising his voice in protest or whether he seeks to quietly sound out his inner life. 


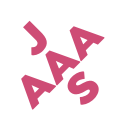

Nathalie Aghoro

Kevin Quashie looks beyond resistance as a paradigm for black aesthetics by introducing considerations on the vulnerability and interiority in African American culture with his book The Sovereignty of Quiet (2012). He strikes a blow for an academic debate that pays attention to the quiet, contemplative aspects of black literature and art. With his conception of quiet subjectivity, he seeks to widen the scope when it comes to "the politics of representation, where black subjectivity exists for its social and political meaningfulness rather than as a marker of the human individuality of the person who is black." He elaborates that "as an identity, blackness is always supposed to tell us something about race or racism, or about America, or violence and struggle and triumph or poverty and hopefulness... . All of this suggests that the common frameworks for thinking about blackness are limited."4 For Quashie, a potential overemphasis on the function of resistance in black cultural production silences other aesthetic expressions. Like Moten, he turns toward the auditory, metaphorically and literally, but chooses to consider its absence and to posit the notion of quiet as expressiveness. As such, his understanding of the quiet does not oppose the significance of political and civil engagement for African American culture, it rather enriches it with a different pathway to black aesthetics by focusing on its expression of inner life and private subjectivity.

In Percival Everett's work, resistance plays a significant role and even the most explicitly quiet character in his 1999 novel Glyph "pushes against social identity and its narrow corners," to use Quashie's turn of phrase. ${ }^{5}$ Overall, Everett's experimental, self-reflexive writings resist easy categorizations, stereotyping, and social pressure, particularly in the context of black identity formations. His poetry and fiction combine socio-cultural reflections with critical debates on literary aesthetics-a combination which defies prescriptive stipulations seeking to monitor what African American literary representation should be or look like in order to be considered as authentic-a word that often merely serves as a stand-in for the confirmation of its user's worldview. The editors of Perspectives on Percival Everett (2013), Keith Mitchell and Robin Vander, observe Everett's "refusal as an African American writer to be categorized at all" and his advocacy for a broader, less reductive and conventional understanding of American literature with his writing of "counternarratives to what he sees as the myopic vision of mainstream publishers and the reading public." As a consequence, his writings invite readers to reflect critically on the representative functions assigned to African American authors in the U. S.-American literary canon.

Everett's novel Erasure (2001) features one of the most resonant examples of vocal resistance to the potentially discriminating classifications on the literary market at the turn of the twenty-first century. In the book, a publisher seeks to explain the lacking success of the fiction written by the protagonist and character-writer Thelonious Ellison, a fictional amalgamation of Thelonious Monk and Ralph Ellison, of 


\section{3}

Voice, Silence, and Quiet Resistance in Percival Everett's Glyph

jazz and writing. According to the agent, his works are not marketable and do not appeal to a wider audience simply because he is "not black enough," for which the writer demands an explanation:

"What's that mean, Yul? How do they even know l'm black? Why does it matter?" "We've been over this before. They know because of the photo on your first book. They know because they've seen you. They know because you're black, for crying out loud."

"What, do I have to have my characters comb their afros and be called niggers for these people?"

"It wouldn't hurt."7

Instead of answering to the socio-culturally more relevant and critical question "why does it matter?" the agent suggests that Ellison should conform to dominant expectations that dehumanize his characters and turn them into flat stereotypes for the sake of higher sales figures. As Lesly Larkin observes in Race and the Literary Encounter (2015), Erasure "acknowledge[s] the role readers play in seeing or not seeing stereotypes, in shaping the racial meaning of texts, and in being shaped by texts." It does not need more than a photograph of the author to render him hypervisible up to the point that any of his literary expressions not relating to (his) blackness are actively ignored and ultimately silenced by editors, readers, and critics. "Stunned into silence," Ellison decides to protest by writing a satirical, outspoken novel called My Pafology with the aim to expose such pigeonholes in the media and on the literary market. 9 Ironically, however, the satire becomes the toast of critics and readers in Erasure precisely because its display of mediated stereotypes is misinterpreted as authentic characterization-proving, as Larkin writes, that "reading is a social practice." 10 In other words, Erasure illustrates the power of interpretation by recording the encounter of a literary work with the public and exposes the necessity for socio-culturally (self-)reflective reading practices.

When Ron Shaver tells Percival Everett that he considers "Erasure ... a big protest" in a 2004 BOMB magazine interview, Everett objects, arguing that the novel's precursor, his 1999 fictional work Glyph, is "almost a bigger protest than Erasure. Erasure is like describing a rattlesnake's bite. Am I protesting rattlesnakes?" "With his terse answer, Everett invites readers to pause and (re)consider their assessment of the novel. If, as he observes, Erasure is a description, then what does make Glyph a protest? Perhaps, the novel is more of a performance, a fictional protest that begins with a resounding act of resistance: The refusal to speak.

I understand the protest in Glyph to reside in the vocal void that occupies its literary soundscape, an aural absence through which Ralph, the character-narrator, seeks to preserve his humanity while exposing himself as a textual construct at the same 


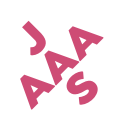

Nathalie Aghoro

time. Ralph explicitly notes early on in the novel that he is and will remain quiet: "I was a baby fat with words, but I made no sound."12 Fittingly, readers learn that the story takes place during his early childhood. These will, for a long time, remain the only two physical features that the four-year-old child prodigy divulges about himself. Wellversed in philosophy and literary theory, he is hyperaware of his textual and thus inaudible function as a narrative instance; an awareness that is mirrored in his rejection of social norms by his refusal to speak to any of the other characters in the fictional world that he describes. His dual role as a narrator who repeatedly addresses, among others, Wittgenstein's, Barthes's, and Derrida's philosophical discussions on language and as a diegetic character who entertains intersubjective relationships in the storyworld establishes two planes upon which writing is pitched against orality. On the one hand, Ralph exposes the narrative situation as mere linguistic facade lacking material substance. He comments on his existence as a purely linguistic sign and hence invites us to read his narration as an academic novel that scrutinizes critical practices through metafictional play. On the other hand, the repeated references to his silence evoke a literary soundscape that refers to a tangible world. In this (story) world, Ralph's self-chosen silence not only disconcerts his parents, but attracts the attention of "mad" scientists because of his allegedly deviant behavior. As he begins to write, his intellectual capacities come out and he ends up in a prison where government intelligence agencies who view him as a valuable asset experiment on him.

In the following, I will demonstrate that Glyph creates a literary soundscape of the quiet voice to reflect on its function in both the politics and aesthetics of resistance. The foregrounded absence of orality in Everett's novel proves that Glyph explores the boundaries and possibilities of self-determination in the American socio-political context as it pitches the acoustics of silence and voice against the mute textuality of the book. After considering how Glyph establishes a literary soundscape through vocal silence, I will address Ralph's favoring of text over speech and the consequences of his quiet resistance to social pressure. In order to do so, I will focus on the not necessarily linear, but rather diffusive movements from orality to writing and back again that the novel performs in content and form in order to generate an experimental literary space where the refusal to speak becomes a resonant expression of resistance.

\section{Voice and Literary Quiet}

In Everett's novel, the quiet voice is an integral part of its literary soundscape and its acoustic absence is the marker for the potential of sound to manifest itself eventually. According to sound studies scholar Salomé Voegelin, "Silence ... involves listening and hearing as a generative action of perception." In other words, silence draws attention to the auditory because it stimulates the act of listening as it unfolds in a 
soundscape. Therefore, silence can be defined as "the dynamic locale of anticipation," as Voegelin observes in her book Listening to Noise and Silence (2010).14 The perceived lack of a sound beckons the listener to expect its sounding as an imminent event. In the special case of a voice-i.e., an animated sound conceptually connected to a living body-the presence of a silent human being can trigger such auditory expectations.

Ralph's parents expect the sounding of the baby's voice as the next step in his cognitive development. They seek to teach him his first vocal articulations from the very beginning because, as the young child observes, "they were what they were, sadly, and that was speakers"; in other words, they believe to recognize human subjectivity in a child by its loud auditory proclamations from an infant's scream to the first linguistic utterance. ${ }^{15}$ Their attempts are in vain, but despite Ralph's resistance to fulfilling their expectations, they do not give up: "My parents, ... clawing at speech like sick cats, could not fathom my lack of interest in parroting their sounds. They put their smelly mouths in front of my face, somehow assuming that without an ability to express offense, it could not be experienced." ${ }^{{ }^{16}} \mathrm{He}$ believes that his parents equate the abstention from sounding his voice in protest with equanimity or consent and that his resistance to the social practice of sonic interaction and oral demonstrations of an independent will is unthinkable for them.

Since Ralph introduces himself to the readers as character and narrator of a work of fiction, his quiet voice simultaneously elicits and occupies a literary soundscape in the sense of a void that takes part in shaping the sonic layers of his fictional world precisely because of its failure to sound. To clarify that his silence is not a sign for slow development as his father believes, but a conscientious choice, Ralph decides to let his parents know that he has already acquired the capacity to express himself. "By the age of ten months... he not only comprehended all that they were saying but... was as well marking time with a running commentary on the value and sense of their babbling."17 Bending the novelistic suspension of disbelief to the extreme, he positions himself as a writer from the start and scribbles a note that will fundamentally change the relationship to his parents:

why should ralph speak ralph does not like
the sound of it ralph watches the mouths
of others form words and it looks uncomfortable
lips look ugly to ralph when they are
moving ralph needs books in his crib ralph
does not wish to rely on the moving lips for
knowledge $^{18}$

He formulates his discomfort with any kind of corporeal activity that the sounding of a voice entails. The lips, as part of the mouth, represent the final threshold 


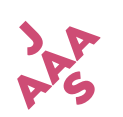

Nathalie Aghoro

that a voice could potentially cross in order to become a free-floating manifestation of his presence in the world. Brandon Labelle explains in Lexicon of the Mouth (2014) that the mouth "is an extremely active cavity whose movements lead us from the depths of the body to the surface of the skin, from the materiality of things to the pressures of linguistic grammars-from breath to matter, and to the spoken and the sounded." "The mouth is thus a location of process and transformation and the lips can be considered as the epitome of a biological exchange between inside and outside, between living environment and inner life, but also between the abstractions of language and the sensory tangibility of the body. Ralph openly refuses to use his mouth to perform the anticipated transformation into a speaking and thinking subject. To affirm that he is not merely trapped in a passive silent condition, he uses writing to reveal the agency and the intellectual impetus behind his abstention from speech and thus contextualizes his silence as an act of resistance. The notion of the quiet reflects this sense of purpose. As a consequence, the disclosure of his preference for the abstractions of writing and his choice to remain quiet represent challenges to the enlightened equation of voice with rational subjectivity both on a metafictional plane and on the level of the storyworld.

Not only does Ralph, the character, let his parents in on his preference of mind over body, writing over speech for the dissemination of knowledge; Ralph, the narrator also cautions the reader that he is a signifier without a referent and "all ... [his] meaning is surface." ${ }^{20}$ As narrative instance, he stands at odds with the fictional convention of suggesting a body or corporeal instance and his self-referential commentary resist any attempt at essentializing the sound of his voice and, by extension, his body. As Julian Wolfreys writes in his discussion of Glyph,

We should be on our guard against "naturalizing" Ralph .... Ralph is an effect of writing, one which transgresses repeatedly through rhetorical devices that contradict their own logic, thereby transgressing the limits of the fictive constitution of the human" and repeatedly exposing his narration as "artifice rather than a natural representation of voice. ${ }^{21}$

Ralph is a linguistic experiment which, in turn, experiments with language in sound and writing. He lays out the scientific questions that he pursues with what he exposes as two related performative acts: His persistent, voluntary silence and the written mediation of his life story.

The question becomes, especially for one who chooses not to speak, whether there is a phenomenological value of the voice itself, whether it has any transcendence. Does the voice have an appearance? ... And does voice, the sounding voice, the speaking voice, carry the same impact as the voice of writing? And can the two work together or against each other, possibly even working to negate meaning altogether? A kind of complicity between sound and sign. ${ }^{22}$ 


\section{3}

Voice, Silence, and Quiet Resistance in Percival Everett's Glyph

This passage-titled "incision" like several other metafictional digressions from the main story-stipulates voice as the linchpin for a phenomenological investigation of the worlding capacities of literature. It posits Glyph as a case study exploring the field of tension in which fictional voice resides. Metafiction and fiction converge in Everett's work to simultaneously display and question connections "between sound and sign" in the auditory imaginary of fiction. The double focus on the speaking voice and the (dead) metaphor of narrative voice in writing expose the elusive insubstantiality of voice that becomes a vehicle between the textual abstractions of language and the concreteness of sonic representation in the storyworld.

Glyph does not resolve the ambiguous status of voice as sound in text; it rather uses language to create the critical distance to the all too familiar that is necessary for a phenomenological examination. This becomes most apparent in poems that Everett's character-narrator writes about the corporeal sites where the sounding of voices takes place: Mouth and ear. The title of the poem "Labyrinth" not only refers to the linguistic designation for the inner ear and implies the locatedness of hearing in the body, it is also programmatic for its aesthetics of sound and writing. In the poem, the inner ear is a labyrinth, a "complex maze, / one puzzle embracing another, / the sound contained in petrous bone."23 Language entices the reader into a lyrical world where words resonate like sound waves when they reach a human body of flesh and blood. Sarah Wyman, who analyzes the republished versions of the poems in Everett's poetry collection re: $f$ (gesture) from 2006, observes that "through techniques of defamiliarization, the body meets us in an aestheticized version, rendered in a verbal medium that insists we take a second look in our effort to understand."24 Through metaphor, the familiar body part becomes an accessible, yet mythical space through which sound moves in mysterious ways. Thus, "Labyrinth" molds the complexity of the organ and the corporeal processing of sound in writing and, moreover, symbolizes the effort that one needs to make in order to navigate the pitfalls and dead ends involved in the act of listening.

Whether voice has an appearance is the question that Ralph grapples with in a poem called "Larynx"-the voice box where human breath turns into sound and speech. The poem deals with the inherently transitory body of voice that is locatable, however, in the corporeal site promoting its becoming. ${ }^{25}$ In Wyman's words, this is a poem that "speak[s] the body and the personal connection such bodies enable. They trust the perceptions for gaining knowledge in the human thirst to sensually experience the phenomenal world. The performative act of Everett's observation affirms bodily existence..., memorializes human interconnection."26 The comparison between the mother's and the child's throats in "Larynx" connects them through kinship and constructs their corporeal existence through language. 
In the novel, embedded stylistic digressions like the poems that function "as elaborate sound-scapes" and self-referential reflections serve as catalysts for the establishment of a literary soundscape that serves as a background for Ralph's absent voice. ${ }^{27}$ Thus, the literary quiet in Glyph refers to the resonant absence of voice in the soundscape of the fictional world, an auditory specter that never materializes, and to the textual constructedness of the narrative. The novel's peculiar character-narrator "transgress[es] the very margin in which his voice is transcribed, and from which it moves in two directions. The first-person narrator is a shuttle of sorts, a phantasmic weaving device that stitches together two incompatible worlds, the fictional and the real."28 The two directions that the novel takes are hence simultaneously bound to demystify the over-determination of the connection between world and word and to resist its complete deconstruction. Word and world, excessively exposed textuality and corporeal materiality are inextricably intertwined in Glyph. Ralph ceaselessly posits their paradoxical connection as existential: "Writing myself into being? I think not... All too aware, am I, of my large ears and frightening silence, a silence so intimidating that my parents run from me."29 With a father who "was a poststructuralist" and a painter for a mother, Ralph has an artist and a critic as parents as much as art and theory engendered the glyph from the title that Ralph, the textual element, represents. ${ }^{30}$ Navigating both word and world in a "self-referential density," Ralph both performs and embodies the intermedial relation between the textualization of language and speech and the representation of real-world experience. $^{31}$

\section{Blackness and the Social Practice of Quiet Resistance}

The human voice reaches out to another with its sounding. As such, it is social by definition. If, in Mladen Dolar's words, "we are social beings by the voice and through the voice," the deliberately quiet voice challenges social dynamics and can be considered as a signifier for a private subjectivity. ${ }^{32}$ Quashie's

notion of quiet is a metaphor for the full range of one's inner life... [which] is not apolitical or without social value, but neither is it determined entirely by publicness. In fact, the interior-dynamic and ravishing-is a stay against the dominance of the social world; it has its own sovereignty. ${ }^{33}$

Along these lines, the choice to remain silent can be understood as quiet resistance to public interpellation. In the case of Glyph's character-narrator who oscillates between word and world, the predilection for the quiet addresses both literary and social conventions, but it also exposes the precarious state of such an existence when the sovereignty of the quiet subject is in the line of fire. 


\section{3}

Voice, Silence, and Quiet Resistance in Percival Everett's Glyph

Ralph's refusal to pronounce words and, thus, to interact with others as a speaker causes his startled parents to consider him a troubled child and to seek help from a psychologist. The denial of corporeal sonic expression in combination with his advanced cognitive skills in the fields of reading and writing-which moreover exceed the intellectual capacities of the adult characters he encounters-disturbs the specialist:

Steimmel, like my parents, was irritated by my refusal to speak. She examined my throat and checked my reflexes with her little hammer. She tried to startle me, hoping to cause me to blurt out something, but I didn't... She pinched me, trying to make me cry out, but only left a silent bruise. ${ }^{34}$

Finally, Steimmel abducts Ralph because she wants to dissect his brain to satisfy her scientific curiosity. This first abduction leads to a series of kidnappings by other scientists and Ralph falls into the hands of a secret government agency that uses him for espionage purposes. Therefore, Ralph's choice not to adhere to the social norms expected from him is considered a capital offense to others who then objectify his body for their own purposes and attempt to break his quiet resistance by radical means.

The world Ralph lives in is governed by the primacy of the visual. This becomes apparent when Ralph remarks that his "readings in genetics and history and current events made it clear that the people on the street were going to find the discrepancy between ... [his] skin color and... [his] abductors' at least notable." 35 He quietly resists mentioning the color of his skin for over fifty pages into the narrative, because it is neither relevant for his textual signification process nor for his self-conception. In the world, however, phenotypes are of acquired importance. Readings give Ralph this insight and he relates this information to the reader, thus exposing the cultural construction of said significance as formed and perpetuated by scientific, social, and historical discourses.

The public significance of visual identification processes turns Ralph's silence into a political act, a purposeful performance of quiet resistance. In his dual role, Ralph links the reality of worldly cultural dominants and their political critique to literary conventions and reading practices influenced by hegemonic discourse. He addresses the reader directly, asking:

Have you to this point assumed that I am white? In my reading, I discovered that if a character was black, then he at some point was required to comb his Afro hairdo, speak on the street using an obvious, ethnically identifiable idiom, [and] live in a certain part of town .... White characters, I assumed they were white (often, because of the way they spoke to other kinds of people), did not seem to need that kind of introduction, or perhaps legitimization, to exist on the page. ${ }^{36}$ 


\section{$3 \%$}

Nathalie Aghoro

With the choice not to advertise his blackness, the rejection of unwritten literary rules, and, possibly, the mere lack of concern with differences in outward appearance, Ralph resists ocularcentric determination. However, when the lack of expressing said resistance could lead to the misreading of a text and the eradication of its political meaning because of learned conventions such as the hegemonic requirement for a "legitimization ... to exist on the page," quiet resistance encounters its limitation. For protest to have an impact, it needs to be expressed. Ralph defies racialization in literature, but social and literary norms force him to broach the issue at least to clarify that he seeks to quietly resist and not merely ignore them.

Ralph sacrifices the "sovereignty of quiet" for a moment due to practical reasons, but not without holding the reader accountable: "It is not important unless you want it to be and I will not say more about it, but a physical description of one kidnapped baby would have to be released to the police." ${ }^{37}$ The simple fact that his parents are looking for him (he is a baby in need of parental care after all, even if he is a surprisingly eloquent one) forces him to relinquish his non-visual, silent, and private position and to become visible for the reading public. Even so, he is aware that his visibility comes at the risk of readers overemphasizing the relevance of his blackness and measuring his story exclusively in terms of what it relates about "the black experience."38 $\mathrm{He}$ is aware of the "process of 'ethnic overdetermination' ... in a politically asymmetrical situation," as Michel Feith has observed. ${ }^{39}$ Accordingly, with his comment to the reader, Ralph establishes that "race"... is neither to be denied nor overemphasized. It is one of the variables in the text, but in no way is it the most important one."40 Ralph is aware of the impact socio-cultural dynamics have on the subject (i.e., the characters in the storyworld of Glyph) and knows that these also shape the reception of his narration. As a result, he even contradicts his own poststructuralist emphasis on textuality with an ironic tone when he remarks that "we do not give the creature reality enough credit, choosing to see it sitting out there as either a construct of ours or an infinitely regressing cause for the trickery of our senses."41 However, this reality encompasses both the subjection of the individual to social pressures and the humanity of the person that does not necessarily seek to be considered as a representative of any kind-a humanity Ralph seems to salvage and protect by choosing not to sound his voice.

The public exposure of his rejection of speech in combination with his analytical talents in reading and writing bring him into a position where he cannot avoid contact with a social reality external to the philosophical, literary, and theoretical considerations he spends his time with. Ralph calls characters he encounters in the world he lives in "speakers," well aware of the fact that they notice his non-conformance to social norms and, therefore, fear and obsess over him. There is "fear, genuine fear" in the voice of one of his abductors whose companion wants to dissect Ralph's brain, a 
fate the toddler escapes from by running into the arms of some undercover agents who incarcerate him in prison to turn him into a military asset called "Defense Stealth Operative 1369." ${ }^{\prime \prime 3}$ Jacqueline Berben-Masi proposes that the reason for Ralph's aversion to speech is that he assigns it "to the realm of violence." She concludes from Ralph's literary expressions in particular that he considers speech to be "an unnatural and unpleasant reaction to forces that escape the subject's control and destroy it." ${ }^{\prime 4}$ In the reality of Glyph's fictional world, Ralph is indeed subjected to constant control and monitoring by people who consider him being a fascinating asset, and an equally dangerous and useful object of investigation. As Berben-Masi notes, "Whether subject of psychological experimentation destined ultimately for dissection, spy for the military against the industrial complex, love object of frustrated parental instincts or sexual prey, Ralph is never allowed to be just Ralph, never permitted to live out his own personal destiny."45 $\mathrm{He}$ is subjected to the will of others and his (social) identity is assigned to him because the rogue members of academic, religious, and governmental institutions underestimate and objectify him despite (or even because of) his extraordinary faculties.

Ralph's existential struggle is the search for individual freedom, self-expression, and self-determination in a society that assigns him the role of a captive-a struggle that he negotiates in written form and by abstaining from using his voice. Feith refers to the literary references implied in Ralph's captivity when he reads Glyph as a slave narrative. He argues that not only the name of Ralph's father Douglas suggests that the "connection with slave narratives may not be fortuitous"-and indeed Frederick Douglass as a namesake would be consistent with the long list of writers featured as characters and references in the novel-but also that "in slave narratives, writing often represents the acquisition of a voice and subject status." ${ }^{36}$ Along these lines, I understand Ralph's engagement with literature and philosophy as the steering toward a medium that allows him to explore and to experiment with adequate ways to convey his exposure to a violent and clamorous world of "speakers" who have no qualms proclaiming their opinions to him. With the simultaneous emphasis on his declared refusal to speak, he draws attention to the difficulties entailed in breaking free from his assigned role in such a socio-cultural context and living on his own terms.

On his quest for self-determination, Ralph's quiet voice also challenges the topos of raising one's voice as an expression of agency and political activism well-established in figures of speech. Read in concert with post-Civil Rights literature, his quiet resistance resonates with the auditory imaginaries developed by James Baldwin, Toni Cade Bambara, Amiri Baraka, and others who, according to Carter Mathes, use "the political and aesthetic qualities of sound [to] resist the implicit and explicit perpetuations of white supremacy as they are narrated and enacted across the bodies 


\section{5}

Nathalie Aghoro

of black Americans." For Mathes, the usage of literary soundscapes in African American literature after 1965 is "a form of resistance to the political silence imposed on black voices." ${ }^{\text {"37 }}$ He recognizes

an inclination ... among certain African American experimental writers to conceptualize their work through critical understandings of sound. This approach to sonic narration reflected a desire to imagine alternate configurations of subjectivity and resistance outside the frameworks for social transformation that had generally been reflected in the linearity and hyper-visibility of the Civil Right and Black Power movements. ${ }^{48}$

Everett's novel Glyph displays a similar inclination, but also adds other perspectives to these configurations of resistance precisely because of the willful self-silencing of the character-narrator's voice. It is this refusal of a voice to abide by political and literary conventions that reveals the complex dynamics of racialization in social interactions and reading practices described earlier and expresses Ralph's wish for alternate ways of writing himself into being. Consequently, Ralph, the narrator, creates an alternative auditory space when he plays with the literary and philosophical intertexts that inform Glyph. In short insertions to the main text, philosophers and writers reflect on universal concerns of literature and aesthetics, which Wolfreys fittingly refers to as "conversational vignettes."49 The dialogic tone of their fictional encounters suggests that these thinkers are sitting together for a moment to discuss their ideas. Among the famous interlocutors in Glyph are Ralph Ellison who meets with Aristophanes, Zora Neale Hurston who talks with Roland Barthes, Maurice Merleau-Ponty who joins Jacques Lacan, and Socrates who comes together with James Baldwin in the following passage:

SOCRATES: Tell me, Jimmy, how do things go these days?

BALDWIN: Things go fine.

SOCRATES: You know, I envy your art. Being able to create a world, build people, lie the way you do so convincingly.

BALDWIN: I wouldn't call it lying.

SOCRATES: Very well. But I have a question for you. You create a world and to do that you have to draw on the world we know and then re-create. Is that close to correct?

BALDWIN: More or less.

SOCRATES: So in order to render a world as you do, you must fully comprehend the world from which you draw your material and substance.

BALDWIN: Actually, it is the act of creating the world of my fiction that allows me to understand the so-called real world. ${ }^{50}$

Socrates and Baldwin are represented here as two theoreticians who share an interest in the relation between word and world. Their imagined encounter is anach- 
ronistic and thus impossible in the "so-called real world," but the spatial arrangement of their spoken words on the page exemplifies literature's capacity to establish a performative framework where they can exchange ideas even if canonical classifications in literary history may potentially silence their commonalities. The imaginary orchestration of their voices in the literary quiet is written in a non-formal tone that foregrounds the intimacy of the direct exchange and dramatizes its intersubjective dynamics. They function as narrative pauses in which Ralph, who imagines these encounters, establishes an atemporal literary soundscape in which the focus shifts from the particularities of social context to general reflections on the art of writing. The oral exchange between Socrates and Baldwin shows them as individuals actively listening to each other, thus establishing a counterpoint to the frantic policing of Ralph's quiet resistance by his social environment. The result is a utopian literary soundscape where resonant voices transgress the confining dimensions of canonical demarcations and call for a universal ethics of listening.

\section{Voice and Writing-Voice in Writing}

Keeping quiet can be a shield against a subject's exposure to judgment, conflict, and external determination. In Glyph, the quiet voice represents an act of self-preservation as much as it is a provocation. Ralph's capacity to read and write exposes his silence as a willful act of resistance that does not sit well with the powers at work in his world. Just as he deliberately withholds information from the reader that he later reveals to debunk ocularcentric processes of othering in literary reception, he unsettles the social dynamics in the storyworld because of his non-normative behavior and unmasks the strategies used by institutions and individuals to retain their sense of supremacy.

Overall, voice in Glyph expands the possibilities for a literary aesthetics of resistance. Percival Everett's experimentation with the sound of silence in literature demonstrates the broad range and flexibility of the auditory imaginary when one listens to it at what Moten called "the scene of objection."

\section{Notes}

1 Percival Everett, Glyph (New York: Faber and Faber, 1999), 9.

2 Kevin Quashie, The Sovereignty of Quiet: Beyond Resistance in Black Culture (Minneapolis: University of Minnesota Press, 2003), 134; Fred Moten, In the Break: The Aesthetics of the Black Radical Tradition (Minneapolis: University of Minnesota Press, 2003), 1.

3 Moten, In the Break, 68.

4 Quashie, Sovereignty of Quiet, 3.

5 Ibid., 135. 


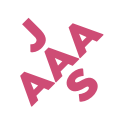

Nathalie Aghoro

6 Keith B. Mitchell and Robin G. Vander, "Changing the Frame, Framing the Change: The Art of Percival Everett," in Perspectives on Percival Everett, ed. Keith B. Mitchell and Robin G. Vander (Jackson: University Press of Mississippi, 2013), xii-xiii.

7 Percival Everett, Erasure (Minneapolis, MN: Graywolf Press, 2001), 43.

8 Lesley Larkin, Race and the Literary Encounter: Black Literature from James Weldon Johnson to Percival Everett (Bloomington: Indiana University Press, 2015), 128.

9 Everett, Erasure, 43.

10 Larkin, Race and the Literary Encounter, 127.

11 Ron Shaver, "Percival Everett," BOMB Magazine, July 1, 2004, https://bombmagazine.org/ articles/percival-everett/.

12 Everett, Glyph, 9.

13 Salomé Voegelin, Listening to Noise and Silence: Towards a Philosophy of Sound Art (London: Continuum, 2010), 11.

14 Ibid., 93.

15 Everett, Glyph, 6.

16 Ibid., 5 .

17 Ibid., 6 .

18 Ibid., 8.

19 Brandon LaBelle, Lexicon of the Mouth: Poetics and Politics of Voice and the Oral Imaginary (London: Bloomsbury Academic, 2014), 1.

20 Everett, Glyph, 31.

21 Julian Wolfreys, In Theory: Tropes, Subjectivities, Responses and Responsibilities (London: Continuum, 2010), 146.

22 Everett, Glyph, 136.

23 Ibid., 98.

24 Sarah Wyman, "Charting the Body: Percival Everett's Corporeal Landscapes in re: $f$ (gesture)," in Perspectives on Percival Everett, ed. Keith B. Mitchell and Robin G. Vander (Jackson: University Press of Mississippi, 2013), 126. As Wyman notes, part of the poems "initially appear in ... Glyph" but "the poems differ in re: f(gesture) as they are written in the voice of an adult lover" (130).

25 Everett, Glyph, 112.

26 Wyman, "Charting the Body," 134.

27 Ibid., 131.

28 Wolfreys, In Theory, 146.

29 Everett, Glyph, 16.

30 Ibid., 6 .

31 Ibid., 95 .

32 Mladen Dolar, A Voice and Nothing More (Cambridge, MA: MIT Press, 2006), 14.

33 Quashie, Sovereignty of Quiet, 6.

34 Everett, Glyph, 77.

35 Ibid., 54. 


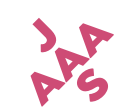

Voice, Silence, and Quiet Resistance in Percival Everett's Glyph

36 Ibid.

37 Ibid.

38 A parallel between Ralph and his namesake Ralph Ellison suggests itself at this point. In his discussion of Ellison's Invisible Man (1952), Moten argues that "the mark of invisibility is a visible, racial mark; invisibility has visibility at its heart. To be invisible is to be seen, instantly and fascinatingly recognized as the unrecognizable" (68). In this sense, the hegemonic overdetermination of phenotypes dehumanizes the black subject by turning her/him into a "black box" exclusively identified as an unknowable other and nothing else. Ralph's quiet resistance is equally threatened by the mark of invisibility when the fascination with the color of his skin overrides his literary and intellectual endeavor.

39 Michel Feith, "Hire-a-Glyph: Hermetics and Hermeneutics in Percival Everett's Glyph," Canadian Review of American Studies 43, no. 2 (2013): 312, DOI: 10.3138/cras.2013.019.

40 Ibid.

41 Everett, Glyph, 16.

42 Ibid. 6.

43 Ibid., 89, 139.

44 Jacqueline Berben-Masi, "Percival Everett's Glyph: Prisons of the Body Physical, Political, and Academic," in In the Grip of the Law: Trials, Prisons and the Space Between, ed. Monika Fludernik and Gret Olson (New York: Peter Lang, 2004), 236-37.

45 Ibid., 225.

46 Feith, "Hire-a-Glyph," 307.

47 Cather Mathes, Imagine the Sound: Experimental African American Literature after Civil Rights (Minneapolis: University of Minnesota Press, 2015), 10.

48 Ibid., 18-19.

49 Wolfreys, In Theory, 156.

50 Everett, Glyph, 99-100.

51 Moten, In the Break, 1.

\section{About the Author}

Nathalie Aghoro is an assistant professor of North American literary and cultural studies at the Catholic University of Eichstaett-Ingolstadt with an interest in auditory culture, postmodern and contemporary literature, and media theory. Her book Sounding the Novel: Voice in Twenty-First Century American Fiction (Universitätsverlag Winter, 2018) examines the sonic mediality of voice in the works of Richard Powers, Karen Tei Yamashita, Jennifer Egan, and Jonathan Safran Foer.

Contact: Nathalie Aghoro; Catholic University of Eichstaett-Ingolstadt; American Studies; nathalie.aghoro@ku.de. 